\title{
Assessment of Endemic Goiter of Children in Eastern Sudan (Kassala State) Using Ultrasonography and ELISA
}

\author{
Shazaly N. Khojaly ${ }^{1}$, Mohamed Yousef ${ }^{1,2}$, Mohammed E. Mohamed ${ }^{1}$, Ikhlas A. Hassan", \\ Mogahid M. A. Zidan ${ }^{3,4^{*}}$, Auis Bashir1, Magdi Hassan' ${ }^{1}$ \\ ${ }^{1}$ College of Medical Radiologic Science, Sudan University of Science and Technology, Khartoum, Sudan \\ ${ }^{2}$ Batterjee Medical College for Science and Technology, Jeddah, Saudi Arabia \\ ${ }^{3}$ Faculty of Radiology and Nuclear Medicine Sciences, The National Ribat University, Khartoum, Sudan \\ ${ }^{4}$ Medical Imaging Technology Department, Al-Ghad International College for Applied Medical Science, Abha, Saudi Arabia \\ Email: Dr.shazalynader@gmail.com, mohnajwan@gmail.com, *jojo.zidan999@gmail.com, ikhlas_abdelaziz@yahoo.com
}

How to cite this paper: Khojaly, S.N., Yousef, M., Mohamed, M.E., Hassan, I.A., Zidan, M.M.A., Bashir, A. and Hassan, M. (2018) Assessment of Endemic Goiter of Children in Eastern Sudan (Kassala State) Using Ultrasonography and ELISA. Open Journal of Medical Imaging, 8, 25-30. https://doi.org/10.4236/ojmi.2018.83004

Received: April 10, 2018

Accepted: August 11, 2018

Published: August 14, 2018

Copyright $(9) 2018$ by authors and Scientific Research Publishing Inc. This work is licensed under the Creative Commons Attribution International License (CC BY 4.0).

http://creativecommons.org/licenses/by/4.0/

\begin{abstract}
Thyroid gland is one of most important endocrine glands in the body. It plays vital role in growth control and its measurements tends to change in respect to age, sex, weight and ethnic group of the individual. This study aimed to assess endemic goiter and to estimate the measurement of normal thyroid gland dimensions and thyroid hormones level in school-aged children using Ultrasonography and ELISA Technique in Eastern Sudan (Kassala state). A total of 100 subjects is $6-18$ years (43 males, 57 females), and mean of age (9.73 \pm 2.54 years). This study was done in the period from April 2016 to February 2017. All the subject undergone thyroid ultrasound and thyroid hormone level test. Subjects with history of goiter were excluded from the study, by thyroid dimension (length, height and diameter). Thyroid volume was estimated using ellipsoid formula and thyroid hormones (TSH, T3 and T4) using Toso full automation. The study revealed that 12 subjects of the study (12\%) with goiter, 7 female (7\%) and 5 males (5\%) with age ranged 6 11 years with increase in TSH and T3 and decrease in T4 level. The mean of thyroid volumes for normal subject and subject of goiter are 4.93 $\pm 0.63,5.4 \pm$ $1.4 \mathrm{~mL}$, respectively, and TSH, T3, T4 (1.8 $\pm 0.97,2.4 \pm 0.86 \mathrm{UIu} / \mathrm{nL}),(3.61 \pm$ $0.32,3.8 \pm 0.55 \mathrm{Pg} / \mathrm{Nl}),(1.35 \pm 1.23 \mathrm{ng} / \mathrm{DI}$ level respectively). It concluded that there was positive correlations between the age and the thyroid volume $(p=0.65)$. It increases with increase of the age. The Rt lobe is larger than the Lt lobe; the thyroid volume is higher in male than female, and this study found the TSH and T3 decreased with ages while T4 increased with ages in normal subject; TSH and T3 level increased and T4 level decreased in goiter children.
\end{abstract}




\section{Keywords}

Thyroid Gland, TSH, Goiter, Hormone Level

\section{Introduction}

Thyroid Ultrasonography has established itself as a popular and useful tool in the evaluation and management of thyroid disorders. The true measurement of thyroid size is important in examination of the thyroid and evaluation of pathologies.

Today ultrasound and scintigraphy used in examining the adult thyroid gland due to the risk of radiation in determining the size, location and function of thyroid gland of children. Therefore, the ultrasound is the most method to determine thyroid gland size in children. Anatomically the thyroid gland is a highly vascular, brownish-red gland located anteriorly in the lower neck, extending from the level of the fifth cervical vertebra down to the first thoracic. The gland varies from an $\mathrm{H}$ to a $\mathrm{U}$ shape and is formed by 2 elongated lateral lobes with superior and inferior poles connected by a median isthmus. The thyroid gland makes a hormone called thyroxine. This hormone controls how fast the body converts food into energy (metabolism). Parathyroid hormone (PTH) is made by the parathyroid glands. It controls the amount of calcium and phosphorus in the blood [1]. The aim of this study is to survey the epidemic goiter in Sudanese children using ultrasound and ELIZA technique.

\section{Materials and Methods}

This study was done in the Kassala state during the period from 2016 up to 2017, the ultrasound system used is general electric (GE) medical system, made by Yokogawa medical system, Ltd., 7 - 127 Asahigaoka 4-chome, Hino-shi Tokyo, Japan. Model 2302650 with serial of 1028924YM7 and manufacturing date of April 2005, a grey scale real-time ultrasound machine, fitted with a $10 \mathrm{MHz}$ transducer was used for the study, all the data collected in data collecting sheet and analysis by Microsoft Excel Worksheet (v2010) and SPSS (v20).

\subsection{Eliza Machine}

Fluorescence Enzyme Immunoassay, LED illuminant, non-flow cell/TOP-TOP photometry method 36 tests per hour antigen antibody reaction: 10 minutes, France.

\subsection{Volunteer}

A total of 100 students from the Kassal state primary schools were involved in this study. The ethics and research committee approved the study. For the purpose of this research, approval was obtained from the Ministry of Education in Kassala state. After that, approval was obtained from the schools where the re- 
search was conducted and the consent of the students' parents was taken.

\subsection{Exclusion Criteria}

Subjects with clinical evidence of thyroid disease were excluded. Furthermore, any student above 18 years, were excluded from the study. The data were collected and analyzed using SPSS for windows version 17 and excel.

\subsection{Measurement Technique for Thyroid Volume}

The thyroid volume measured by using ultrasound general electric (GE) medical system, and linear probe $10 \mathrm{MHz}$, the children told to lie supine with hyperextension of the neck, transverse (x), anteroposterior (y) and sagittal (z) length of right lone, left lobe and isthmus were measured and the volume were calculated by the ellipsoidal formula its volume is approximated using height $x$ width $\times$ depth $\times$ a correction factor.

\subsection{Measurement Technique for Thyroid Hormones}

In this study, we took blood samples from the cases and then separated them with a polystyrene centrifuge and then they were stored in coolers until we were transferred to Kassala state laboratory center, to be analyzed and taken levels of hormones by TOSO Biosciece ALA-360, THS measured by UIu/nL, T4 ng/DI and $\mathrm{T} 3 \mathrm{Pg} / \mathrm{nL}$.

\section{Results}

This study aimed to assess the epidemic goiter in the school aged children of Kassala state, and tested 100 subject the age between 6 - 18 year (43 males, 57 females), By using Ultrasonography and ELISA Technique, this study founded 13 cases (13\%) with goiter, the Although thyroid ultrasound is a good diagnostic tool for assess the thyroid volume.

\section{Discussion}

In recent decades, the WHO has changed the diagnostic criteria for goiter. The diagnosis of goiter used to be based on palpation, but now it is based on volume measurement.

Using sonography, volume measurement of the thyroid gland is especially easy to obtain because the gland has a different echogenicity compared with adjacent soft tissues [2]. The aim of this study was to evaluate epidemic endemic goiter and to estimate the measurement of normal thyroid gland dimensions and thyroid hormones level in school-aged children using Ultrasonography and ELISA Technique in Eastern Sudan (Kassala state). Regarding to a total of 100 subjects $6-18$ years ( 43 males, 57 females), mean of age ( $9.73 \pm 2.54$ years), this study was done in the period from April 2016 to February 2017. The thyroid volume by ultrasound and the thyroid hormones level were done for all the subjects. All the subjects with history of goiter were excluded from the study. In ul- 
trasound scan for this study we uses, Mindary machine, linear probe $10 \mathrm{MHz}$ and for thyroid hormones (TSH, T3 and T4) used Toso full automation. The study revealed that 12 subjects of the study (12\%) with goiter, 7 female (7\%) and 5 males (5\%) with age ranged (6 - 11 years) with increase in TSH and T3 and decrease in T4 level. The mean of thyroid volume for normal subject and subject of goiter is $0.93 \pm 0.63,5.4 \pm 1.4 \mathrm{~mL}$, respectively, and TSH, T3, T4 $(1.8 \pm 0.97,2.4$ $\pm 0.86 \mathrm{UIu} / \mathrm{nL}),(3.61 \pm 0.32,3.8 \pm 0.55 \mathrm{Pg} / \mathrm{Nl}),(1.35 \pm 1.23 \mathrm{ng} / \mathrm{DI}$ level respectively). In the study carried out by Khojaly et al. [3], the mean of thyroid volume for no mal subject and subject of goiter, $(5.03 \pm 0.92,5.72 \pm 1.77 \mathrm{~mL})$ respectively. The study showed that the mean thyroid volume with respect to age of normal children most cases in this study is $(3.88 \pm 0.57)$ for both males and females in age group of ( 9 - 11 years) followed by $(3.18 \pm 0.33)$ age group of $(6-8$ years) (Table 1$)$.

This study showed strong significant between the thyroid volume and age for healthy children and children with goiter (Table 1 and Table 4) and showed significant correlation between them (Figure 1). This agrees with the study done by Yousef $\mathrm{M}$ et al. in 2010. Also this study founded there is no correlation between the subject age and the T3, T4 and TSH hormones (Figures 2-4). In this study we found 12 children (12\%) with goiter most of them are females in age between (6 - 11 yrs.) These agree with the study done by Yousef M et al. in 2012 [4].

This study showed the mean of thyroid volume in males is greater than that in the females (Table 2 and Table 3 ) this agree with the study done by Mohammed Yousef et al. in 2011 [5].

Table 1. Mean Volume of the thyroid gland and TSH, T3 T4 with respect to age of normal children.

\begin{tabular}{cccccc}
\hline \multirow{5}{*}{ Age (y) } & \multicolumn{5}{c}{ Table Column Head } \\
\cline { 2 - 6 } & $\mathrm{N}$ & Volume (ml) & TSH (UIu/nL) & T3 (Pg/nL) & T4 (ng/DI) \\
\hline $6-8$ & 31 & $3.18 \pm 0.33$ & $2.54 \pm 1.09$ & $3.69 \pm 0.36$ & $1.4 \pm 0.35$ \\
$9-11$ & 35 & $3.88 \pm 0.57$ & $2.61 \pm 1.23$ & $3.77 \pm 0.31$ & $1.17 \pm 0.17$ \\
$12-14$ & 17 & $4.72 \pm 0.95$ & $1.88 \pm 0.93$ & $3.59 \pm 0.52$ & $1.1 \pm 0.24$ \\
$15-17$ & 2 & $6.7 \pm 0.7$ & $1.2 \pm 0.63$ & $3.15 \pm 0.09$ & $1.89 \pm 0.63$ \\
$18-20$ & 2 & $6.21 \pm 0.09$ & $1.19 \pm 0.02$ & $3.53 \pm 0.04$ & $1.14 \pm 0.06$ \\
\hline
\end{tabular}

Table 2. Mean Volume of the thyroid gland and TSH, T3 T4 with respect to age of normal children (male).

\begin{tabular}{cccccc}
\hline \multirow{5}{*}{ Age (y) } & \multicolumn{5}{c}{ Table Column Head } \\
\cline { 2 - 6 } & $\mathrm{N}$ & Volume $(\mathrm{ml})$ & $\mathrm{TSH}(\mathrm{UIu} / \mathrm{nL})$ & $\mathrm{T} 3(\mathrm{Pg} / \mathrm{nL})$ & $\mathrm{T} 4(\mathrm{ng} / \mathrm{DI})$ \\
\hline $6-8$ & 14 & $3.04 \pm 0.37$ & 3.051 .09 & $3.41 \pm 0.37$ & $1.33 \pm 0.1$ \\
$9-11$ & 21 & $4.14 \pm 1.3$ & $2.93 \pm 1.2$ & $3.83 \pm 0.25$ & $3.83 \pm 0.25$ \\
$12-14$ & 7 & $4.2 \pm 1.2$ & $2.34 \pm 1.09$ & $3.54 \pm 0.37$ & $0.97 \pm 0.2$ \\
$18-20$ & 1 & 6.28 & 1.2 & 3.59 & 1.19 \\
\hline
\end{tabular}


Table 3. Mean Volume of the thyroid gland and TSH, T3 T4 with respect to age of normal children (female).

\begin{tabular}{cccccc}
\hline \multirow{2}{*}{ Age $(\mathrm{y})$} & \multicolumn{5}{c}{ Table Column Head } \\
\cline { 2 - 6 } & $\mathrm{N}$ & Volume $(\mathrm{ml})$ & $\mathrm{TSH}(\mathrm{UIu} / \mathrm{nL})$ & $\mathrm{T} 3(\mathrm{Pg} / \mathrm{nL})$ & $\mathrm{T} 4(\mathrm{ng} / \mathrm{DI})$ \\
\hline $6-8$ & 21 & $3.37 \pm 0.46$ & $2.21 \pm 0.84$ & $3.97 \pm 0.41$ & $1.46 \pm 0.4$ \\
$9-11$ & 24 & $4.51 \pm 0.9$ & $2.33 \pm 1.28$ & $3.75 \pm 0.34$ & $1.19 \pm 0.16$ \\
$12-14$ & 9 & $4.77 \pm 0.76$ & $1.53 \pm 0.74$ & $3.63 \pm 0.64$ & $1.21 \pm 0.23$ \\
$15-17$ & 3 & $6.78 \pm 0.021$ & $1.2 \pm 0.64$ & $3.15 \pm 0.09$ & $1.89 \pm 0.63$ \\
\hline
\end{tabular}

Table 4. Mean Volume of the thyroid gland and TSH, T3 T4 with respect to age of goiter children.

\begin{tabular}{cccccc}
\hline \multirow{2}{*}{ Age $(\mathrm{y})$} & \multicolumn{5}{c}{ Table Column Head } \\
\cline { 2 - 6 } & $\mathrm{N}$ & Volume $(\mathrm{ml})$ & TSH $(\mathrm{UIu} / \mathrm{nL})$ & $\mathrm{T} 3(\mathrm{Pg} / \mathrm{nL})$ & $\mathrm{T} 4(\mathrm{ng} / \mathrm{DI})$ \\
\hline $6-8$ & 4 & $4.01 \pm 0.32$ & $2.56 \pm 0.52$ & $4.4 \pm 0.56$ & $1.47 \pm 0.19$ \\
$9-11$ & 9 & $6.01 \pm 1.24$ & $2.35 \pm 0.99$ & $3.53 \pm 0.29$ & $1.13 \pm 0.28$ \\
\hline
\end{tabular}

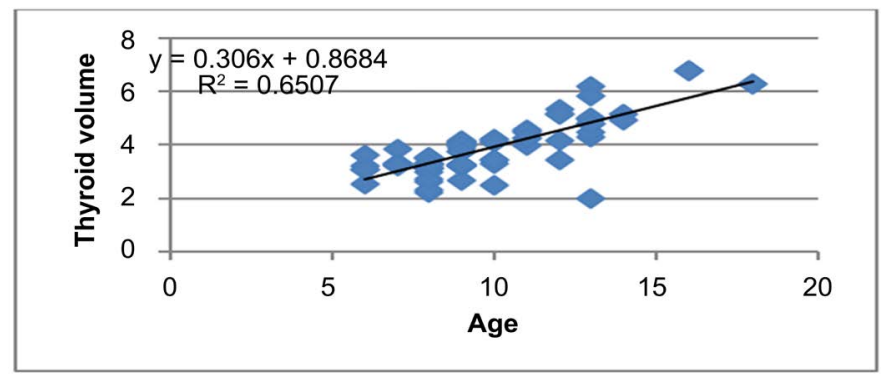

Figure 1. Repesent thecorrelation of thyroid volume and subject age $(\mathrm{p}=0.65)$.

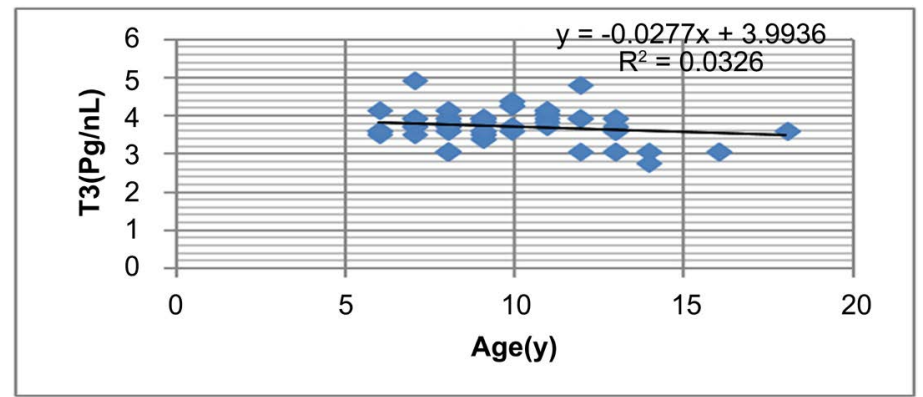

Figure 2. Repesent correlation of T3 and subject age $(\mathrm{p}=0.03)$.

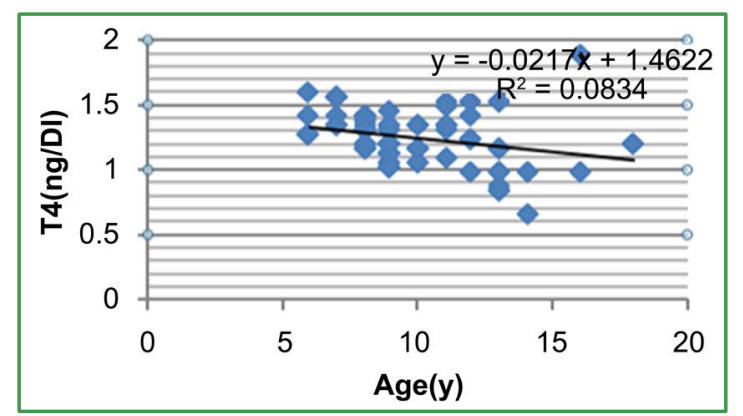

Figure 3. Repesent correlation of T4 and subject age $(\mathrm{p}=0.08)$. 


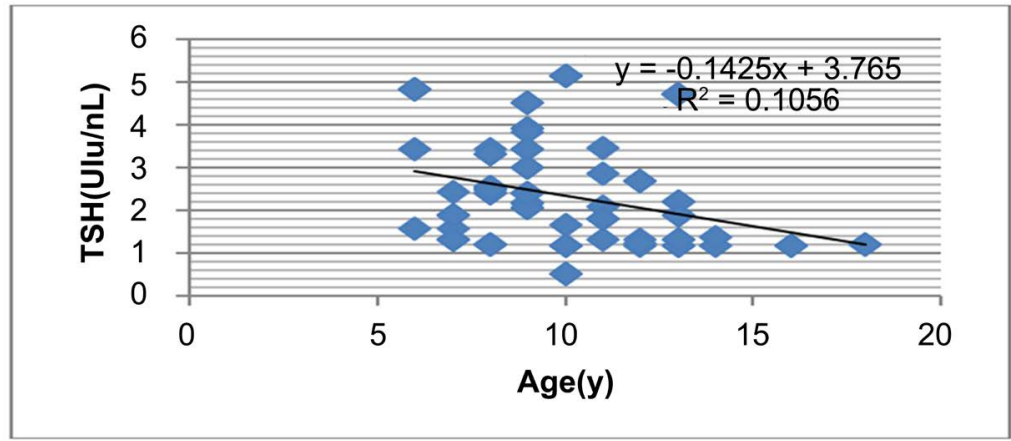

Figure 4. Represent correlation of TSH and subject age $(\mathrm{p}=1)$.

\section{Conclusion}

In conclusion there is strong correlation between the age and the thyroid volume for both normal and goiter children. The volume of the right lobe of the gland was greater than the left in both sexes. The mean thyroid volume in the males is greater than that in the females, and TSH and T3 decrease with ages while T4 increases with ages in normal subject, while the TSH and T3 level increases and T4 level decreases in goiter children. Local reference of thyroid volume and the goiter parentage, were established in Kassala state.

\section{Conflicts of Interest}

The authors declare no conflicts of interest regarding the publication of this paper.

\section{References}

[1] Ivarsson, S.A., Person, P.H. and Ericson, U.B. (1989) Thyroid Gland Volume as measured by Ultrasonography in Healthy Children and Adolescent in a Non-Iodine Deficient Area. Acta Paediatrica, 78, 633-634. https://doi.org/10.1111/j.1651-2227.1989.tb17951.x

[2] Jamesone, J.L. and Weetman, A.P. (2001) Disorders of the Thyroid Gland. In: Braunwald, E., Fauci, A.S., Kasper, D.L., Hauser, S.L., Longo, D.L. and Jameson, J.L., Eds., Harrison's Principles of Internal Medicine, 15th Edition, McGraw-Hill, New York, NY, 2060-2061.

[3] Khojaly, S., Yousef, M., Garelnabi, M., Zidan, M.M.A., Bashir, A., Babiker, M.S., Madwi, E.M.I. and Ibrahim, A.K.A. (2018) Assessment of Endemic Goitre of Children in Eastern Sudan (Red Sea State) Using Ultrasonography and ELISA. Global Advanced Research Journal of Medicine and Medical Sciences, 7, 28-33.

[4] Yousef, M., Suleiman, A., Ali, N.I., Hassan, A.M. and Eltom, K.H. (2012) Characterization of Radioimmunoassay and Scintigraphy as Diagnostic Tools for Goiter in Sudanese Patients. Ozean Journal of Applied Sciences, 5, 151-157.

[5] Yousef, M., Sulieman, A., Ahmed, B., Abdella, A. and Eltom, K. (2011) Local Reference Ranges of Thyroid Volume in Sudanese Normal Subjects Using Ultrasound. Research Journal of Thyroid Research, 2011, Article ID: 935141. 